\title{
Prevalence and Predictors of Contraceptives Use among Women Aged (15-49 years) with Induced Abortion History in Ghana
}

\author{
Mohammed Gazali Salifu $\mathbb{D D}^{1}$ and Kamaldeen Mohammed ${ }^{2}$ \\ ${ }^{1}$ Ministry of Health, Ghana, Post Office Box M44, Accra, Ghana \\ ${ }^{2}$ Department of Geography, Western University, 1151 Richmond Street, N6A 3K7, London, Ontario, Canada \\ Correspondence should be addressed to Mohammed Gazali Salifu; mohammedgazali17@gmail.com
}

Received 1 June 2020; Revised 30 July 2020; Accepted 14 August 2020; Published 28 August 2020

Academic Editor: Diego A. S. Silva

Copyright (c) 2020 Mohammed Gazali Salifu and Kamaldeen Mohammed. This is an open access article distributed under the Creative Commons Attribution License, which permits unrestricted use, distribution, and reproduction in any medium, provided the original work is properly cited.

\begin{abstract}
Background. The incidence of abortion in Ghana ranges from 27 per 1000 to 61 per 1000 women, causing gynecological complications and maternal mortality. The use of modern contraceptives and its associated factors among women aged 15-49 years have been documented. However, utilization of modern contraceptives specifically among women with induced abortion history is underreported. This study therefore aimed at determining the proportion and identifying predictors of contraceptives use in this underreported population. Methods. This study used secondary data from the 2017 Ghana Maternal Health Survey (GMHS) for the analysis. The analysis is on a weighted sample of 3,039 women aged (15-49 years) with a history of induced abortion. Both descriptive and inferential methods were employed. The chi-square test, univariate and multivariate logistic regression techniques were used to assess statistical associations between the outcome variable and the predictors. Statistical significance was set at $95 \%$ confidence interval and $p$ values $\leq 0.05$. Results. Out of the 3,039 participants, $37 \%$ (95\% CI: $34.6,38.84$ ) used contraceptives. We identified women' age, union, place of residence, knowledge of fertile period, total pregnancy outcomes, and region as strong significant $(95 \% \mathrm{CI}, p \leq 0.05)$ predictors of post induced abortion contraceptives use. Conclusion. Contraceptives use among this vulnerable population is low. Therefore, there is a need to provide widespread access to postabortion contraception services and enhance efforts to efficiently integrate safe abortion practices law into health services in Ghana.
\end{abstract}

\section{Introduction}

Globally, the proportion of unsafe abortions in developing countries is $49.5 \%$ [1]. Sub-Saharan Africa (SSA) accounts for $61 \%$ of all deaths due to unsafe abortion with a case fatality rate for Africa in 2008 approximated at 520 per 100,000 unsafe abortions [2]. In Ghana, $20 \%$ of women in reproductive age (15-49 years) have experienced induced abortion during their lifetime (ICF, Ghana Health Service (GHS), 2018). Incidences of abortion in Ghana range from 27 per 1000 to 61 per 1000 women [3]. Admissions to gynecological wards and maternal mortality can be attributed to induced abortions in Ghana [4].

Despite the 1985 Ghanaian law accommodating safe abortion practice on certain medicosocial grounds, there have been observed delays in the formulation and implementation of policies to integrate the law into health services [5]. Factors such as lack or insufficient knowledge on safe abortion, stigma related to unintended pregnancy, religious beliefs, and implicit nature of the abortion law have significantly influenced safe abortion practice negatively in Ghana $[5,6]$.

These challenges associated with the delays in the implementation of comprehensive abortion care in Ghana make the use of modern contraceptives imperative and a reliable option towards reducing the high rates of unwanted pregnancies [7-9], induced abortions [9], maternal deaths [10], and sexually transmitted infections (STIs) [8].

The use of modern contraceptives and its associated factors among women age (15-49 years) have been documented in Ghana [9, 11-16]. However, utilization of modern contraceptives specifically among women with induced 
abortion history is underreported despite their vulnerability. Relatedly, only $19 \%$ of women aged 15-49 years with a history of induced abortion receive contraception support in Ghana (ICF, Ghana Health Service (GHS), 2018). In addition, several studies reported in Ghana and elsewhere have highlighted varying proportions and predictors of contraceptives use among women with induced abortion history [17-20].

This study, therefore, used a nationally representative survey [21] to report the national proportion and identify factors significantly influencing the use of modern contraceptives among this age group of women (15-49 years) with induced abortion history. This will provide valuable information for policymakers and implementers to make informed and evidence-based decisions regarding policy formulation and implementation on reproductive health policies and programs.

\section{Materials and Methods}

2.1. Study Design and Data Source. This study is a retrospective cross-sectional design using the Ghana Maternal Health Survey (GMHS) conducted in 2017. The GMHS is a nationally representative special survey, which collects data relating to women, children, birth, household, and other feminine variables covering all regions and districts of the country. The survey was first conducted in 2007 and also in 2017.

2.2. Sampling Approach and Study Population. For this current Ghana Maternal Health Survey (GMHS) 2017, 27,001 households were selected for the sample, of which 26,500 were occupied at the time of fieldwork. Data were collected from participants with a questionnaire through a multistage probability sampling technique. During the first stage, proportional sampling was used to select 900 enumeration areas (EAs) (including 466 EAs in urban and 434 EAs in rural areas, respectfully) to reflect the sizes of EAs with independent sampling in each stratum. Secondly, a household listing was carried out from 25 January to 9 April 2017 in all the selected EAs to serve as a sampling frame for the selection of households in the second stage. The interviewed households were 26,324 , resulting in a response rate of $99 \%$. With the interviewed households, 25,304 eligible women were recruited for individual interviews. However, interviews were completed with 25,062 women. The response rate of the completed interview was $99 \%$. The sampling procedure is extensively detailed in the complete final report of the Ghana Maternal Health Survey 2017 (ICF, Ghana Health Service (GHS), 2018) [21]. In this present study, our analysis is on a weighted sample of 3,039 women aged 15-49 years out of the 25,062 reproductive age women data analyzed in the 2017 GMHS.

2.3. Inclusion Criteria. The study included women in their reproductive ages between 15 and 49 years who have ever been in a situation in which she or someone else had to do something to end her pregnancy.
2.4. Exclusion Criteria. The exclusion criteria were those who met the inclusion criteria above but had missing data.

2.5. Outcome Variable. The outcome variable was "current usage of any method of contraceptives (modern or traditional) to delay or avoid getting pregnant." The responses were coded as either "Yes" or "No."

2.6. Independent Variables Measures. We included several theoretical pertinent sociodemographic variables. Women age group (14-19, 20-24, 25-29, 30-34,35-39, 40-44, and 45-49), religious status (Christianity, Islam, traditional, and others), age at first intercourse ( $<16$ and 16 or above), health insurance (yes or no), knowledge of fertility (yes or no), current union (yes or no), region (Eastern, Greater Accra, Northern, Upper East, Upper West, Volta, Eastern, Central, Ashanti, Western, and Brong Ahafo), education (primary, JHS, SHS or above, and no education), place of residence (rural or urban), and gravidae (1-3, 4-5, and 6 or more). Furthermore, variables were recoded where appropriate to produce a meaningful sample for the analysis.

2.7. Statistical Analysis. This analysis used both descriptive and inferential methods. Descriptive statistics used are mainly frequencies and percentages. Chi-square tests, univariate and multivariable techniques were used to assess statistical associations between the outcome variable and the predictors.

The chi-square test of independence was used to statistically identify factors associated with the outcome variable looking at their estimated confidence intervals (CI), and $p$ values less than or equal to 0.05 were used to retain and include the variables in a univariate logistic regression analysis. In the univariate analysis, variables with $p$ values $<0.05$ were simultaneously included in a multivariable logistic regression model to generate adjusted odds ratio (AOR) with their corresponding $95 \%$ confidence intervals.

This statistical approach was implemented in STATA (Stata Statistical Software: Release 16. College Station, TX: StataCorp LP) software. The complex survey command "svy" was used to estimate means, proportions, and confidence intervals (CI). The final model goodness of fits was checked using the "svylogitgof" command [22]. The results revealed no evidence of a lack of fit with our model in significantly predicting contraceptives use.

2.8. Ethics. The Ghana Health Service Institutional Review Board (IRB) approves the Demographic Health Surveys study protocol, survey instruments, and materials before commencement of the surveys. Individual consent was also obtained during the data collection process. Data were then used after approval was obtained. Furthermore, this study concept was presented to ICF for permission to use the datasets in this study, and approval was duly granted before its use. All terms of use have been observed. 


\section{Results}

3.1. Descriptive Statistics. A total of 3,039 women met the inclusion criteria for the study. The mean and standard deviation age in years of the women was 32.93 (8.32). Almost $37 \%$ (95\% CI: $34.6,38.84$ ) of the participants used contraceptives. The mean and standard deviation age in years of respondents using contraceptives was 33.11 (8.09). The participants who had education above primary school level were $73.43 \%$. Approximately, $67 \%$ of participants were in union (either married or cohabitating with a man). Majority of participants were Christians (91.16\%), and $68.35 \%$ of participants lived in urban areas. Greater Accra and Ashanti regions cumulatively constituted $51.1 \%$ of all participants (Table 1).

In Table 2, $770(70.33 \%)$ of contraceptives users were in a union, and $393(37.71 \%)$ and $737(62.29 \%)$ of participants using contraceptives lived in rural and urban areas. Among participants using contraceptives, 1,031 (91.87\%) were Christians. 347 (31.86\%) contraceptives users had sexual intercourse below age 16. Furthermore, 941 (83.19\%) of contraceptives users were registered with health insurance (Table 2).

3.2. Predictors of Contraceptives Use. Chi-square tests revealed respondents' current age (95\% CI: $\chi^{2}=106.90$, $p \leq 0.001)$, union (95\% CI: $\left.\chi^{2}=11.56, p \leq 0.05\right)$, educational level (95\% CI: $\left.\chi^{2}=17.6039, p \leq 0.01\right)$, residence $(95 \% \mathrm{CI}$ : $\left.\chi^{2}=29.89, p \leq 0.001\right)$, knowledge of the fertile period $(95 \%$ CI: $\chi^{2}=14.74, p \leq 0.001$ ), and gravidae (95\% CI: $\chi^{2}=18.88$, $p \leq 0.001)$ to be significantly associated with contraceptives use (Table 3).

A univariate and multivariate logistic regression was used to identify further significant predictors of contraceptives use (Table 3). At the univariate level, women aged $30-34(\mathrm{OR}=0.61,95 \% \mathrm{CI}: 0.38-0.98, p \leq 0.05)$, 35-39 (OR $=0.51,95 \%$ CI: $0.31-0.83, p \leq 0.01), \quad 40-44$ $(\mathrm{OR}=0.37,95 \% \mathrm{CI}: 0.22-0.62, p \leq 0.001)$, and $45-49$ $(\mathrm{OR}=0.30,95 \% \mathrm{CI}: 0.18-0.48$ were significantly less likely to use contraceptives compared with women aged 15-19 (Table 3). Participants in a union were 1.32 (CI: 1.09-1.59, $p \leq 0.005)$ times significantly more likely to use contraceptives than those not in a union. Also, participants from Ashanti (OR $=1.82,95 \% \mathrm{CI}: 1.21-2.74, p \leq 0.005)$, Northern ( $\mathrm{OR}=2.20$, 95\% CI: 1.19-4.08, $p \leq 0.05)$, Brong Ahafo (OR $=2.06,95 \% \mathrm{CI}: 1.28-3.31, p \leq 0.005)$, and Eastern $(\mathrm{OR}=2.27,95 \% \mathrm{CI}: 1.47-3.49, p \leq 0.001)$ regions were more likely users of contraceptives compared to participants from Central region (Table 3 ).

Also, the probability of using contraceptives among participants with SHS level of education was 0.74 (95\% CI: $0.55-0.99, p \leq 0.05)$ times less likely compared to those with only primary level of education. Rural dwellers were 1.55 (95\% CI: $1.26-1.90, p \leq 0.001)$ times more likely users of contraceptives compared with urban dwellers. Women who had their total pregnancy outcomes between 4 and 5 were 0.68 (95\% CI: $0.55-0.84, p \leq 0.001$ ) times less likely to use contraceptives compared with women with 1-3 total pregnancy outcomes (gravidae) (Table 3). Furthermore, women who knew their fertile period were 1.63 (95\% CI: $0.38-0.98, p \leq 0.05)$ times more likely to use contraceptives than those who do not know. At the multivariate level, age of respondents, union, region, residence, gravidae, and knowledge of the fertile period remained significant predictors while educational level became insignificant predictor after controlling for other predictive factors (Table 3 ).

\section{Discussions}

This study was carried out to estimate the proportion and identify predictors of contraceptives use among women with induced abortion history. We estimated 36.69\% (95\% CI: $34.6,38.84)$ contraceptives use in this population. The estimated proportion is lower compared to similar studies carried out by Makenzius et al., Mekuria et al., and Opoku [18-20]. However, a study carried out in Western Nigeria showed a much lower proportion of contraceptives use [17]. The differences in proportions observed may be attributed to the differences in medical counselling and guidance services received on contraception after abortion episodes, as women tend to take up contraception when counselled properly after any abortion episode [23].

The findings also revealed that older women aged 30-34, 35-39, 40-44, and 45-49 are less likely to use contraceptives relative to younger ones (15-19 years); this corroborates a study conducted by Abebe [24]. However, our finding is contrary to studies carried out by Mekuria et al. and Maxwell et al. $[19,25]$. Adolescents have been identified as a highly sexually active group; so, many health advocacy programs in Ghana, especially those on contraception have focused on them, so this might be responsible for the observed contraceptives use differences identified across the various age groups. Women aged 20-29 years have also been reported to have the highest proportion of abortions in most countries [26]. There is the need for strategies to increase contraception uptake through counselling among older women, improve access to postabortion services, and enhance health service provider training and supervision on postabortion contraception [18]. Also, stigma by health service providers affects women contraception uptake after induced abortion and needs to addressed as well [27].

This study finding also observed that participants in union (married or cohabitating) have higher odds of using contraceptives than those not in a union, which is similar to other studies [18, 28-31]. Other studies have also observed contraceptives use among married women when they have at least eight deliveries and birth intervals less than 24 months between two children [32]. In addition, male involvement in family planning consultation increases their responsibility for contraception [32].

Women living in rural areas had higher odds of contraception than those in urban areas. However, rural women access to maternal and child health services are lowest compared to those in urban areas [33]. In addition, effective postabortion care services are mostly inadequate in villages [34]. Nonetheless, urban women contraception use is low, and a significant proportion of them also experience 
TABLE 1: Background characteristics of respondents $(N=3,039)$.

\begin{tabular}{|c|c|c|}
\hline Variable & Frequency & Percentage \\
\hline \multicolumn{3}{|l|}{ Age } \\
\hline $15-19$ & 115 & 3.516 \\
\hline $20-24$ & 446 & 14.45 \\
\hline $25-29$ & 629 & 20.85 \\
\hline $30-34$ & 576 & 18.74 \\
\hline $35-39$ & 515 & 17.36 \\
\hline $40-44$ & 399 & 13.54 \\
\hline $45-49$ & 359 & 11.53 \\
\hline \multicolumn{3}{|l|}{ Educational level } \\
\hline Primary & 503 & 16.68 \\
\hline JHS & 1222 & 41.29 \\
\hline SHS and above & 1011 & 32.14 \\
\hline No education & 303 & 9.891 \\
\hline \multicolumn{3}{|c|}{ Religious distribution } \\
\hline Christianity & 2751 & 92.16 \\
\hline Islam & 244 & 6.276 \\
\hline Traditional & 8 & 0.2365 \\
\hline Others & 36 & 1.325 \\
\hline \multicolumn{3}{|l|}{ Contraceptives use } \\
\hline Yes & 1130 & 36.69 \\
\hline No & 1909 & 63.31 \\
\hline \multicolumn{3}{|l|}{ Residence } \\
\hline Rural & 925 & 31.65 \\
\hline Urban & 2114 & 68.35 \\
\hline \multicolumn{3}{|l|}{ Union } \\
\hline Yes & 2002 & 66.51 \\
\hline No & 1037 & 33.49 \\
\hline \multicolumn{3}{|l|}{ Region } \\
\hline Western & 388 & 13 \\
\hline Central & 248 & 8.125 \\
\hline Greater Accra & 567 & 26.05 \\
\hline Volta & 212 & 6.005 \\
\hline Eastern & 364 & 10.62 \\
\hline Ashanti & 644 & 25.05 \\
\hline Brong Ahafo & 383 & 9.493 \\
\hline Northern & 86 & 0.7622 \\
\hline Upper East & 69 & 0.4839 \\
\hline Upper West & 78 & 0.4042 \\
\hline
\end{tabular}

reproductive ill-health [35], but generally, contraception uptake among rural women in Ghana relative to urban women is on the increase $[12,15]$. Furthermore, our study revealed that women who know their fertile period are more likely to use contraceptives than those who do not know. This may be attributed to the higher conception odds during this window; however, a study conducted in Nigeria among adolescents has pointed out that not all women restrict intercourse to the safe periods of their cycle [36]. Moreover, there might be other factors that influence unsafe sex practice during this period, which can be exploited further.

While acknowledging the importance of all these predictors highlighted, there is the need for broader methods to satisfy clients varieties and differences regarding contraception [37], effectively addressing the effects of social norms on postabortion contraception, enhanced postabortion counselling services, and encouraging multisectoral
TABle 2: Distribution and chi-square analysis of outcome (contraceptives use) across respondents' characteristics (sociodemographic, socioeconomic, and abortion-related characteristics).

\begin{tabular}{|c|c|c|}
\hline \multirow{2}{*}{ Variable } & \multicolumn{2}{|c|}{ Contraceptives use } \\
\hline & No $(\%)$ & Yes $(\%)$ \\
\hline \multicolumn{3}{|l|}{ Age } \\
\hline \multicolumn{3}{|c|}{$X 2=106.8983, p \leq 0.001$} \\
\hline $15-19$ & $61(2.84)$ & $54(4.674)$ \\
\hline $20-24$ & $224(11.66)$ & $222(19.28)$ \\
\hline $25-29$ & $347(18.31)$ & $282(25.23)$ \\
\hline $30-34$ & $363(18.75)$ & $18.73(18.73)$ \\
\hline $35-39$ & $334(18.42)$ & $181(15.54)$ \\
\hline $40-44$ & $298(15.84)$ & $101(9.59)$ \\
\hline $45-49$ & $284(14.18)$ & $77(6.96)$ \\
\hline \multicolumn{3}{|c|}{ Union } \\
\hline \multicolumn{3}{|c|}{$X 2=11.5593, p \leq 0.005$} \\
\hline Yes & $1232(64.29)$ & $770(70.33)$ \\
\hline No & $677(35.71)$ & $360(29.67)$ \\
\hline \multicolumn{3}{|c|}{ Educational level } \\
\hline \multicolumn{3}{|c|}{$X=17.6039, p \leq 0.05$} \\
\hline Primary & $320(16.22)$ & $183(17.45)$ \\
\hline JHS & $727(39.73)$ & $495(44)$ \\
\hline SHS & $683(34.81)$ & $328(27.54)$ \\
\hline No education & $179(9.24)$ & $124(11.01)$ \\
\hline \multicolumn{3}{|l|}{ Religion } \\
\hline \multicolumn{3}{|c|}{$X=0.8010, p>0.05$} \\
\hline Christianity & $1720(92.33)$ & $1031(91.87)$ \\
\hline Islam & $162(6.23)$ & $82(6.35)$ \\
\hline Traditional & $4(1.87)$ & $4(0.32)$ \\
\hline Others & $23(1.25)$ & $13(1.45)$ \\
\hline \multicolumn{3}{|c|}{ Residence } \\
\hline \multicolumn{3}{|c|}{$X=29.8850, p \leq 0.001$} \\
\hline Rural & $532(28.14)$ & $393(37.71)$ \\
\hline Urban & $1377(71.86)$ & $737(62.29)$ \\
\hline \multicolumn{3}{|c|}{ Age at first intercourse } \\
\hline \multicolumn{3}{|c|}{$X=0.6218, p \leq 0.05$} \\
\hline$<16$ & $589(30.49)$ & $347(31.86)$ \\
\hline $16+$ & $1320(69.51)$ & $783(68.14)$ \\
\hline \multicolumn{3}{|c|}{ Knowledge of fertile period } \\
\hline $\begin{array}{l}\Lambda-1+1+2, P= \\
\text { Yes }\end{array}$ & $1710(90.25)$ & $1058(94.23)$ \\
\hline No & $199(9.75)$ & $72(5.77)$ \\
\hline \multicolumn{3}{|c|}{ Registered with health insurance } \\
\hline Yes & $1543(80.52)$ & $941(83.19)$ \\
\hline No & $366(19.48)$ & $189(16.81)$ \\
\hline \multicolumn{3}{|c|}{ Gravidae } \\
\hline \multicolumn{3}{|c|}{$X=18.8832, p \leq 0.001$} \\
\hline $1-3$ & $760(39)$ & $516(44.67)$ \\
\hline $4-5$ & $590(32.56)$ & $29(25.24)$ \\
\hline $6+$ & $559(28.44)$ & $323(30.1)$ \\
\hline
\end{tabular}

collaborations in postabortion-related contraception programs formulation and implementation.

4.1. Strengths of the Study. This study is from a nationally representative sample and makes room for generalizability of study findings across Ghana. Also, Demographic and Health Surveys (DHS) are planned properly and well-executed; hence, 
TABLE 3: Univariate and multivariate logistic analyses of predictors of contraceptives use among women who ever had induced abortion (15-49 years).

\begin{tabular}{|c|c|c|}
\hline Variable category & Univariate OR (95\% CI), $p$ value & Multivariate aOR (95\% CI), $p$ value \\
\hline \multicolumn{3}{|c|}{ Sociodemographic } \\
\hline \multicolumn{3}{|c|}{ Age of respondents } \\
\hline $15-19$ & 1 & 1 \\
\hline $20-24$ & $1.01(0.62-1.63), 0.979$ & $0.97(0.60-1.57), 0.903$ \\
\hline $25-29$ & $0.84(0.52-1.35), 0.467$ & $0.76(0.46-1.25), 0.279$ \\
\hline $30-34$ & $0.61(0.38-0.98), 0.043$ & $0.50(0.30-0.85), 0.010$ \\
\hline $35-39$ & $0.51(0.31-0.83), 0.008$ & $0.35(0.20-0.62), 0.000$ \\
\hline $40-44$ & $0.37(0.22-0.616), 0.000$ & $0.25(0.14-0.45), 0.000$ \\
\hline $45-49$ & $0.30(0.18-0.48), 0.000$ & $0.22(0.12-0.41), 0.000$ \\
\hline \multicolumn{3}{|c|}{ Age at first intercourse } \\
\hline$<16$ & 1 & \\
\hline 16 or above & $0.94(0.77-1.14), 0.519$ & \\
\hline \multicolumn{3}{|l|}{ Union } \\
\hline No & 1 & 1 \\
\hline Yes & 1.32 (1.09-1.59), 0.004 & 1.45 (1.20-1.75), 0.000 \\
\hline \multicolumn{3}{|c|}{ Religious affiliation } \\
\hline Christianity & 1 & \\
\hline Islam & $1.02(0.69-1.52), 0.906$ & \\
\hline Traditional & $1.734(0.40-7.56), 0.463$ & \\
\hline Others & $1.17(0.54-2.53), 0.693$ & \\
\hline \multicolumn{3}{|l|}{ Region } \\
\hline Central & 1 & 1 \\
\hline Western & 1.75 (1.12-2.75), 0.015 & $1.58(1.00-2.49), 0.049$ \\
\hline Ashanti & $1.820(1.21-2.74), 0.004$ & $1.87(1.25-2.80), 0.002$ \\
\hline Northern & 2.20 (1.19-4.08), 0.012 & $1.98(1.05-3.72), 0.034$ \\
\hline Brong ahafo & $2.06(1.28-3.31), 0.003$ & $2.07(1.31-3.26), 0.002$ \\
\hline Upper West & $1.06(0.53-2.13), 0.876$ & $0.92(0.44-1.90), 0.819$ \\
\hline Upper East & $1.61(0.80-3.27), 0.184$ & $1.50(0.72-3.13), 0.284$ \\
\hline Greater accra & $1.12(0.72-1.73), 0.612$ & 1.37 (0.87-2.15), 0.175 \\
\hline Volta & $1.52(0.93-2.48), 0.093$ & $1.60(0.97-2.62), 0.175$ \\
\hline Eastern & $2.27(1.47-3.49), 0.000$ & $2.32(1.50-3.60), 0.000$ \\
\hline \multicolumn{3}{|c|}{ Socioeconomic characteristics } \\
\hline \multicolumn{3}{|c|}{ Educational level } \\
\hline Primary & 1 & 1 \\
\hline JHS & $1.03(0.80-1.54), 0.821$ & $0.87(0.66-1.14), 0.322$ \\
\hline SHS or above & $0.74(0.55-0.99), 0.043$ & $0.79(0.56-1.11), 0.173$ \\
\hline No education & $1.11(0.80-1.54), 0.542$ & $1.04(0.73-1.48), 0.831$ \\
\hline \multicolumn{3}{|l|}{ Place of residence } \\
\hline Urban & 1 & 1 \\
\hline Rural & 1.55 (1.26-1.90), 0.000 & $1.31(1.04-1.65), 0.022$ \\
\hline \multicolumn{3}{|c|}{ Registered with health insurance } \\
\hline Yes & 1 & \\
\hline No & $0.84(0.68-1.03), 0.086$ & \\
\hline \multicolumn{3}{|c|}{ Abortion-related characteristics } \\
\hline Gravidae & 1 & 1 \\
\hline $1-3$ & 1 & 1 \\
\hline $4-5$ & $0.68(0.55-0.84), 0.000$ & $0.95(0.75-1.23), 0.733$ \\
\hline 6 or more & $0.92(0.75-1.14), 0.454$ & $1.74(1.35-2.23), 0.000$ \\
\hline \multicolumn{3}{|c|}{ Knowledge of the fertile period } \\
\hline No & 1 & 1 \\
\hline Yes & $1.63(1.08-2.46), 0.020$ & $1.84(1.30-2.60), 0.001$ \\
\hline
\end{tabular}

OR, odds ratio. aOR, adjusted odds ratio. CI, confidence interval. Goodness of fittest. F-adjusted test statistic $=\mathrm{F}(9,680)=0.84$. Prob $>\mathrm{F}=0.5748$.

the data are of high quality. Furthermore, observations with complete dataset meeting the study criteria was large.

4.2. Limitations of This Study. Firstly, the data used for this study were obtained through a cross-sectional study design, hence preventing causations from being inferred. The survey [21] obtained information retrospectively, which has a recall bias since participants self-reported, which spanned a 5-year period prior to the survey. Recall bias has an immense effect on coefficient estimates and overall significant testing, and so, interpretations/use of the findings should be performed cautiously. 
Finally, we did not control for all potential confounders in our analysis.

\section{Conclusion}

We explored the proportion of contraceptives use and its associated significant predictors among women aged 15-49 years with a history of induced abortion. The proportion was low at $37 \%$. Women age, union, place of residence, knowledge of fertile period, gravidae, and region were identified as significant predictors of contraceptives use. We recommend that the Ministry of Health and Ghana Health Service facilitate widespread and easy access to modern contraceptives, provide postabortion contraception services, including guidance and counselling to women who need these services. In addition, we recommend efforts to be enhanced in the formulation and implementation of policies by the Government of Ghana to effectively and efficiently integrate the abortion law into services, and lastly, we recommend that the National Health Insurance Scheme (NHIS) should absorb contraception services as a way of curbing high cost as a potential predictor of its low uptake

\section{Data Availability}

The datasets generated and/or analyzed during the current study are available in the Ghana demographic and health repository, http://dhsprogram.com/data/available-datasets. cfm.

\section{Disclosure}

This research did not receive any specific grant from funding agencies in the public, commercial, or not-for-profit sectors.

\section{Conflicts of Interest}

The authors declare that there are no conflicts of interest regarding the publication of this paper.

\section{Authors' Contributions}

MGS conceptualized the present study. MGS led the data extraction and analysis and wrote the first draft of the manuscript. MGS and MK contributed to the write-up of the different sections of the manuscript. MK and MGS reviewed the draft manuscript and contributed to the final version of the manuscript. All authors read and approved the final manuscript before submission.

\section{References}

[1] B. Ganatra, C. Gerdts, C. Rossier et al., "Global, regional, and subregional classification of abortions by safety, 2010-14: estimates from a Bayesian hierarchical model," The Lancet, vol. 390, no. 10110, pp. 2372-2381, 2017.

[2] I. H. Shah, E. Åhman, and N. Ortayli, “Access to safe abortion: progress and challenges since the 1994 international conference on population and development (ICPD)," Contraception, vol. 90, no. 6, pp. S39-S48, 2014.

[3] S. C. Keogh, E. Otupiri, D. W. Chiu et al., "Estimating the incidence of abortion : a comparison of five approaches in ghana," BMJ Global Health, vol. 5, no. 4, Article ID e002129, 2020.

[4] S. D. Rominski and J. R. Lori, "Abortion care in Ghana: a critical review of the literature," African Journal of Reproductive Health, vol. 18, no. 3, pp. 17-35, 2014.

[5] R. A. . Morhee and E. S. Morhee, "Overview of the law and availability of abortion services in Ghana," Ghana Medical Journal, vol. 40, no. 3, pp. 80-86, 2010.

[6] C. A. Atakro, S. B. Addo, J. S. Aboagye et al., "Contributing factors to unsafe abortion practices among women of reproductive age at selected district hospitals in the Ashanti region of Ghana," BMC Women's Health, vol. 19, no. 1, pp. 1-17, 2019.

[7] A. Amalba, V. Mogre, M. N. A. Appiah, and W. A. Mumuni, "Awareness, use and associated factors of emergency contraceptive pills among women of reproductive age (15-49 years) in Tamale, Ghana," BMC Women's Health, vol. 14, no. 1, pp. 1-6, 2014.

[8] P. A. Apanga and M. A. Adam, "Factors influencing the uptake of family planning services in the Talensi district, Ghana," Pan African Medical Journal, vol. 20, pp. 1-9, 2015.

[9] D. W. Geelhoed, D. Nayembil, K. Asare, J. H. S. Van Leeuwen, and J. Van Roosmalen, "Contraception and induced abortion in rural Ghana," Tropical Medicine and International Health, vol. 7, no. 8, pp. 708-716, 2002.

[10] S. Ahmed, Q. Li, L. Liu, and A. O. Tsui, "Maternal deaths averted by contraceptive use: an analysis of 172 countries," The Lancet, vol. 380, no. 9837, pp. 111-125, 2012.

[11] J. Agyemang, S. Newton, I. Nkrumah, J. M. Tsoka-Gwegweni, and S. N. Cumber, "Contraceptive use and associated factors among sexually active female adolescents in Atwima Kwanwoma District, Ashanti region-Ghana," Pan African Medical Journal, vol. 32, pp. 1-13, 2019.

[12] P. A. Aviisah, S. Dery, B. K. Atsu et al., "Modern contraceptive use among women of reproductive age in Ghana: analysis of the 2003-2014 Ghana demographic and health surveys," BMC Women's Health, vol. 18, no. 1, 2018.

[13] K. Grindlay, P. Dako-gyeke, T. D. Ngo et al., "Contraceptive use and unintended pregnancy among young women and men in Accra, Ghana," PLoS One, vol. 13, Article ID e0201663, 2018.

[14] A. Kebede, S. G. Abaya, E. Merdassa, and T. T. Bekuma, "Factors affecting demand for modern contraceptives among currently married reproductive age women in rural Kebeles of Nunu Kumba district, Oromia, Ethiopia," Contraception and Reproductive Medicine, vol. 4, no. 1, pp. 1-15, 2019.

[15] J. Nonvignon and J. Novignon, "Trend and determinants of contraceptive use among women of reproductive age in Ghana," Etude de La Population Africaine, vol. 28, no. 2, pp. 956-967, 2014.

[16] S. H. Nyarko, "Spatial variations and socio-economic determinants of modern contraceptive use in Ghana : a Bayesian multilevel analysis," PLoS One, vol. 15, no. 3, Article ID e0230139, 2020.

[17] M. A. Lamina, "Prevalence of abortion and contraceptive practice among women seeking repeat induced abortion in Western Nigeria," Journal of Pregnancy, vol. 2015, Article ID 486203, 7 pages, 2015.

[18] M. Makenzius, E. Faxelid, K. Gemzell-Danielsson, T. M. A. Odero, M. Klingberg-Allvin, and M. Oguttu, "Contraceptive uptake in post abortion care-secondary outcomes from a randomised 
controlled trial, Kisumu, Kenya," PLoS One, vol. 13, no. 8, pp. 1-13, 2018.

[19] A. Mekuria, H. Gutema, H. Wondiye, and M. Abera, "Postabortion contraceptive use in Bahir Dar, Ethiopia: a cross sectional study," Contraception and Reproductive Medicine, vol. 4, no. 1, pp. 1-6, 2019.

[20] B. Opoku, "Contraceptive preferences of post-abortion patients in Ghana," Journal of Women's Health Care, vol. 1, no. 2, 2012.

[21] Ghana Statistical Service (GSS), Ghana Health Service (GHS), and ICF Macro. Accra: Ghana Maternal and Health Survey, Ghana Statistical Service, Accra, Ghana, 2017.

[22] K. J. Archer and S. Lemeshow, "Goodness-of-fit test for a logistic regression model fitted using survey sample data," The Stata Journal: Promoting Communications on Statistics and Stata, vol. 6, no. 1, pp. 97-105, 2006.

[23] A. Ceylan, M. Ertem, G. Saka, and N. Akdeniz, "Post abortion family planning counseling as a tool to increase contraception use," BMC Public Health, vol. 9, no. 1, pp. 1-7, 2009.

[24] A. M. Abebe, M. Wudu Kassaw, A. B. Zemariam, and N. Estifanos Shewangashaw, "Coverage, opportunity, and challenges of expanded program on immunization among 12-23-month-old children in woldia town, northeast Ethiopia, 2018," BioMed Research International, vol. 2019, pp. 1-10, 2019.

[25] L. Maxwell, G. Voetagbe, M. Paul, and A. Mark, "Does the type of abortion provider influence contraceptive uptake after abortion? An analysis of longitudinal data from 64 health facilities in Ghana," BMC Public Health, vol. 15, no. 1, pp. 1-9, 2015.

[26] S. Chae, S. Desai, M. Crowell, G. Sedgh, and S. Singh, "Characteristics of women obtaining induced abortions in selected low- and middle-income countries," PLoS One, vol. 12, no. 3, pp. 1-19, Article ID e0177149, 2017.

[27] M. Håkansson, M. Oguttu, K. Gemzell-Danielsson, and M. Makenzius, "Human rights versus societal norms: a mixed methods study among healthcare providers on social stigma related to adolescent abortion and contraceptive use in Kisumu, Kenya," BMJ Global Health, vol. 3, no. 2, pp. 1-13, Article ID e000608, 2018.

[28] M. Asrat, D. Bekele, and S. D. Rominski, "Post-abortion contraceptive acceptance and choice determinants among women receiving abortion care at saint Paul's hospital, Addis Ababa, Ethiopia," Ethiopian Journal of Reproductive Health (EJRH), vol. 10, no. 1, pp. 35-48, 2018.

[29] E. EK and A. Abera, "Safe abortion care, utilization of post abortion contraception and associated factors, jimma Ethiopia," Journal of Women's Health Care, vol. 5, no. 4, 2016.

[30] L. Kokeb, "Utilization of post abortion contraceptive and associated factors among women who came for abortion service: a hospital based cross sectional study," Journal of Family Medicine and Disease Prevention, vol. 1, no. 4, pp. 4-7, 2015.

[31] D. Postlethwaite, J. Lee, M. Merchant, A. Alabaster, and T. Raine-Bennett, "Contraception after abortion and risk of repeated unintended pregnancy among health plan members," The Permanente Journal, vol. 22, pp. 18-058, 2018.

[32] A. Gonie, A. Wudneh, D. Nigatu, and Z. Dendir, "Determinants of family planning use among married women in bale eco-region, Southeast Ethiopia: a community based study," BMC Women's Health, vol. 18, no. 1, pp. 1-10, 2018.

[33] D. Buor, "Determinants of utilisation of health services by women in rural and urban areas in Ghana," GeoJournal, vol. 61, no. 1, pp. 89-102, 2004.
[34] H. B. Johnston, R. Ved, N. Lyall, and K. Agarwal, "Where do rural women obtain postabortion care? The case of Uttar Pradesh, India," International Family Planning Perspectives, vol. 29, no. 4, pp. 182-187, 2003.

[35] R. M. Adanu, J. Seffah, J. K. Anarfi, N. Lince, and K. Blanchard, "Sexual and reproductive health in Accra, Ghana," Ghana Medical Journal, vol. 46, no. 2, pp. 58-65, 2012.

[36] U. Amazigo, N. Silva, J. Kaufman et al., "Nigeria sexual activity and contraceptive knowledge and use among in-school adolescents in Nigeria," International Family Planning Perspectives, vol. 23, no. 1, pp. 28-33, 1997.

[37] M. Samuel, T. Fetters, and D. Desta, "Strengthening postabortion family planning services in Ethiopia: expanding contraceptive choice and improving access to long-acting reversible contraception," Global Health: Science and Practice, vol. 4, no. Supplement 2, pp. S60-S72, 2016. 